\title{
THE DAIRY INDUSTRY IN VIET NAM: A VALUE CHAIN APPROACH
}

\author{
Nguyen Viet Khoi ${ }^{1}$ and Tran Van Dung ${ }^{2}$ \\ ${ }^{1}$ Dept. of Int'l Economics and Business, VNU University of Economics and Business \\ ${ }^{2}$ Department of International Economics and Business, VNU University of Economics
}

\begin{abstract}
Vietnam lies in the area of highest economic and milk consumption growth in the world. Vietnam also increased milk yield reached the second highest in Asia with output milk consumption is increasing rapidly. However, the dairy industry in the country only satisfies more than $20 \%$ of the domestic consumption, the rest is imported from foreign. The retail milk price in Vietnam is very high; however, the raw milk prices relatively low. One explanation is the monopoly of the dairy processor in Vietnam. Three largest processors own $75 \%$ of the dairy market. They take advantage in the negotiation with farmers and actively increase the retiling price. Recently, such investigations on the processor by government officers do not take any effect in the dairy market. There is no rule controlling the increase in price yet the own suffer a lot is the final consumer. The main objective of this paper is providing a close look to value chain and its application in the dairy industry in Vietnam. The authors would offer some solutions to increase the value added in the dairy value chain and improvement in the income distribution in this value chain.
\end{abstract}

\section{KEYWORDS:}

Vietnam Dairy Industry; Dairy Value Chain; Vietnam Value Chain; Global Value Chain; Dairy GVC.

JEL: M10, M11

\section{LITERATURE REVIEW}

Nguyen Viet Khoi (2013) provided a value chain approach to the dairy industry. According to Khoi, there are five main actors taking part in the process of dairy products: Input ingredient, production activities, processing, distribution and consumption. The researcher points out that there is a "potential controversy" in the assessment of the milk between producer and the processing firm which lead to lowering the standard of raw milk and harm the milk producer and the paper also provide that most of the profit lie in the processing firm, which might result from the monopoly in the market. Marcy Lowe and Gary Giraffe (2009) showed us a good view on the dairy value chain in the US - An advanced country in milk production. The value chain has 4 main actors: Inputs, Production, Process and Distribution, Marketing. In the US high technology is applied in most parts. There are concentrated steps in nurturing, harvesting, collecting and processing milk. Every step is carefully controlled and managed. One specific point in the US dairy industry lies in the veterinary system. Although there are many veterinarians (estimated 87.946), there is no large company or agency specialized in providing this service. The result of the paper is that the companies downstream from the dairy producer category, Milk and Dairy Processors, include large, diversified companies that, despite being diversified well beyond milk and dairy products, nonetheless include companies that have higher shares of the dairy market than the largest producer cooperative. Stefano Gerosa and Jakob Skoet (2012) reviewed trends 
in global production and consumption of dairy products as well as the drivers behind increasing production and consumption. The past decades have seen rapid growth in consumption of dairy products in several parts. In addition to growing demand, production growth has been driven by technological change in the sector, which has permitted major increases in productivity and the emergence of large-scale commercial dairy farms. However, small-scale dairy producers in several developing countries have remained at the margin of these developments. The result is that the rapid growth of the dairy sector, and the livestock sector at large, in a setting of weak institutions and governance have given rise to risks with potentially large negative implications for livelihoods, human and animal health and the environment The future contribution of dairy and livestock products to human welfare will depend also on how these issues are addressed. Tong Xuan Chinh (2013) depicted he demand for dairy product in Vietnam. In 2004, the consumption is nearly 580mil litres and it nearly fourth times jumps to 2 bill litres in 2013 according to Tetra Pak. The domestic demand is high; however, the domestic production only satisfies nearly $21 \%$ and the proportion in still in creasing. Vietnam recently has to import most of the dairy products from our foreign and the import trend moves from the US to Australia and New Zealand. The Vietnamese authorities have introduced many rule and instruction on the development of dairy products; nevertheless, the effects are still limited. Tran Huy Cuong and Bui Thi Nga (2012) analysed the factor in the value chain of the fresh milk in Viet Nam. This is one of very few researches in Viet Nam on the value chain of the dairy industry. This research based on both quantitative and qualitative approaches in the case of fresh milk products in the northern area of Vietnam. The research shows that there are 4 main factors in the fresh milk value chain: The farmer- Collector- Processing Firms- Distribution. In this value chain, the processing firms hold the decision and become the main actor, which receives most of the profit. The farmers who spend a lot of time and investment (some are not estimated or numerical in this research) only receive a small proportion of the profit. This paper provides a deeper vision on what is going on in the fresh milk production and distribution in Viet Nam. Truong Minh Huy (2009) overviewed the whole Vietnamese dairy industry using value chain approach. This paper builds up a value chain of three main parts: Dairy input, Purchase and manufacturing, Consumption. In the whole value chain, the author mainly focuses on the farmer income distribution. According to Huy, each year, the dairy farmers gained 8 million VDN per cow on average; however, this income depends on such condition: Price of feed, price of raw milk, diseases and market trend. Generally, the dairy farmer income remains high; however, it is not stable and dependent on other condition. One limitation of this research is the value chain is simple, not mentioning other activities especially supportive activities.

\section{Overview about the dairy industry in Vietnam}

In the last 10 year, Viet Nam has witness the gradual growth of the milk consumption. As can be seen from the graph above, the last decade, the milk consumption in Viet Nam has increased nearly four times with the annual growth of $17 \%$. This is a remarkable growth compared to other industry. We also see an increase in the per capita milk consumption 
International Journal of Managing Value and Supply Chains (IJMVSC) Vol.5, No. 3, September 2014

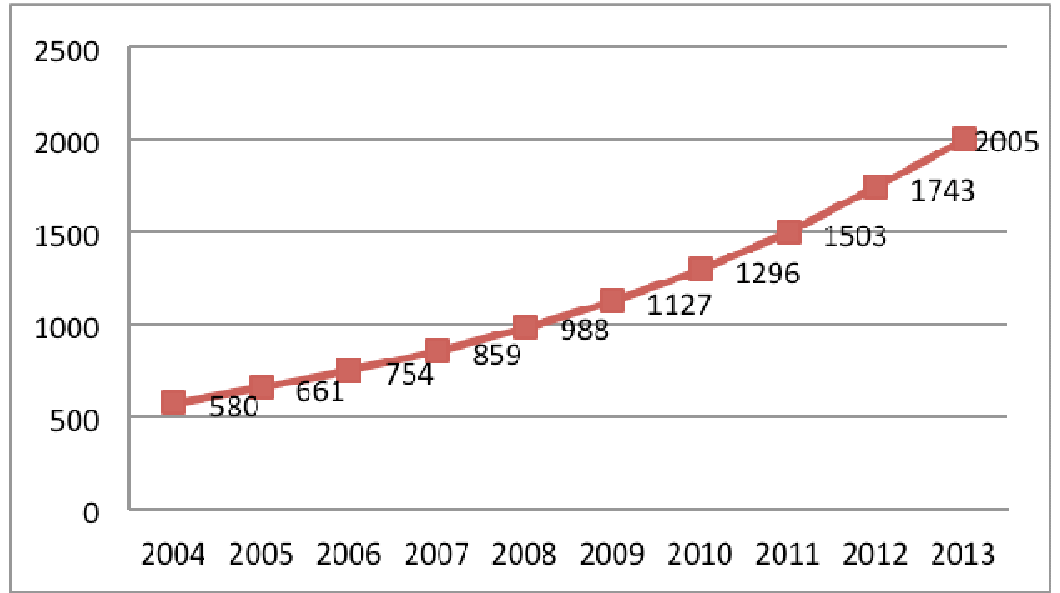

Figure 1: Vietnam total milk consumption from 2004-2013

Source: Chinh (2013) and Author calculation (the 2013 number is expected)

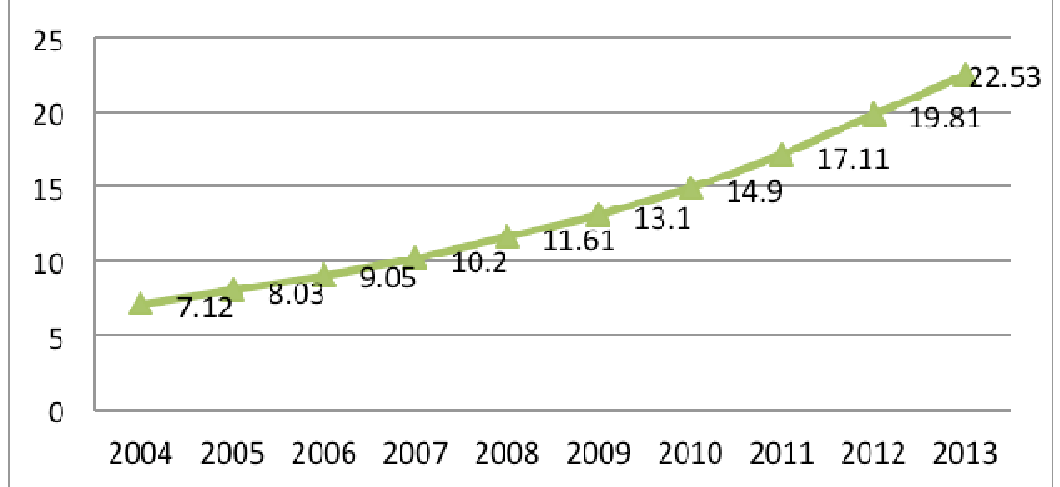

Figure 2: Vietnam per capita milk consumption from 2004-2013

Source: Chinh (2013) and author calculation (the 2013 number is expected)

Viet Nam is not the country with long history of milk production; however, in the last few years, Vietnamese people have realized the importance of milk products and spend more on this nutria drink. The growth rate is quite high on average; nevertheless, Viet Nam is still in the low milk consumption area ( $<30 \mathrm{kilos} / \mathrm{capita} /$ year). This might be a big chance for milk producer in the near future.

Most milk products in Viet Nam are designed for under 3 year olds babies and the elder. There is a huge market for daily milk consumption and mature specialized milk According to Khoi (2013) $10 \%$ of Vietnamese population in the two big cities, namely Ho Chi Minh City and Ha Noi has been consuming $78 \%$ of dairy products. This data shows an inequality in the consumption of milk products.

According to Gerosa and Skoet (2012) investing in 144 countries, we have the elasticity ${ }^{1}$ of the dairy product in the below table:

${ }^{1}$ The income elasticity of expenditure estimates the percentage increase in expenditure on the food category resulting from a one percent increase in income. The numbers reported are simple unweight averages of estimates for the individual countries included in each income group. 
Table 1: The elasticity of consuming products

Source: Gerosa and Skoet 2012

\begin{tabular}{|l|c|c|c|c|}
\hline & $\begin{array}{c}\text { Low-income } \\
\text { countries } \\
(\mathrm{N}=28)\end{array}$ & $\begin{array}{c}\text { Lower middle- } \\
\text { income } \\
\text { countries } \\
(\mathrm{N}=36)\end{array}$ & $\begin{array}{c}\text { Middle- } \\
\text { income } \\
\text { countries } \\
(\mathrm{N}=36)\end{array}$ & $\begin{array}{c}\text { High-income } \\
\text { countries } \\
(\mathrm{N}=44)\end{array}$ \\
\hline Food beverages and tobacco & 0.81 & 0.77 & 0.70 & 0.54 \\
\hline Beverages and tobacco & 1.73 & 1.13 & 0.92 & 0.67 \\
\hline Cereals & 0.59 & 0.49 & 0.34 & 0.08 \\
\hline Meat & 0.80 & 0.76 & 0.69 & 0.53 \\
\hline Dairy & 0.83 & 0.79 & 0.72 & 0.55 \\
\hline Fish & 0.69 & 0.64 & 0.56 & 0.42 \\
\hline Fats, oils & 0.60 & 0.50 & 0.37 & 0.15 \\
\hline Fruits & 0.66 & 0.60 & 0.51 & 0.36 \\
\hline Other foods & 1.82 & 1.23 & 0.98 & 0.70 \\
\hline
\end{tabular}

Note: The income elasticity of expenditure estimates the percentage increase in expenditure on the food category resulting from a one percent increase in income. The numbers reported are simple unweight averages of estimates for the individual countries included in each income group. Viet Nam - A Lower middle-income countries have the relatively high dairy elasticity 0.79 , which might be a reason for the fast growth of the milk industry in Viet Nam.

\section{Traditional value chain}

Historically, Vietnam did not get used to with dairy catering and milk usage. The first dairy cows appeared in Vietnam since the early XX century; however, it only became popular since the 1990s.

Before the Re Innovation in 1986, dairy farming in Vietnam was managed by state-owned dairy farm. The size of these dairy farms was limited with a few hundred cows. The largest one was Moc Chau Dairy farm with approximately 1000 heads. The value chain was quite simple at that time. Dairy farms produce raw milk then sell to the state-owned Distribution Companies. These companies then sold it to the final customer with a fixed price prearranged by the authority. This type of market did not encourage dairy farms or distributors to develop. Therefore, the productivity and the number of cows reduced as a result.

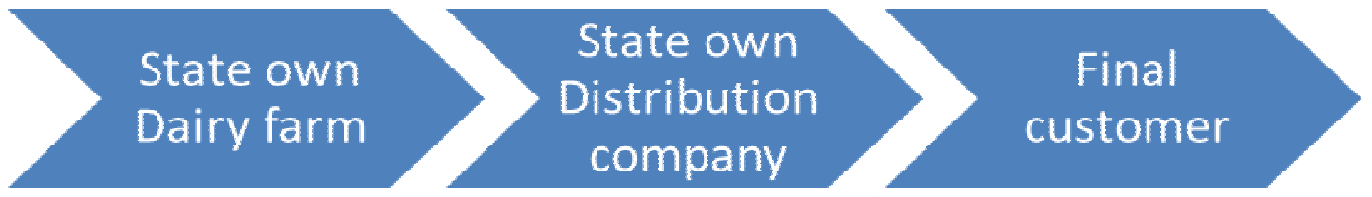

Figure 3: Dairy value chain before "Doimoi"

In the period of 1986- 2000, the "Doimoi" period changed almost every corner of the economy, consisting dairy industry. The development of the economy motivated the increasing trend of dairy farm. Dairy cows not only appeared in state own farms but also spread out other regions, especially the neighboring of large cities like Hanoi and Ho Chi Minh City. As the low starting point of the dairy sector, the scale of dairy farm and processing factory was limited. They satisfied only the demand in a province or a small town. The value chain during this time is improved; however, it still remained dispersed. In this value chain, the role of each actor seemed to be equal and there was no controlling role in this value chain. 


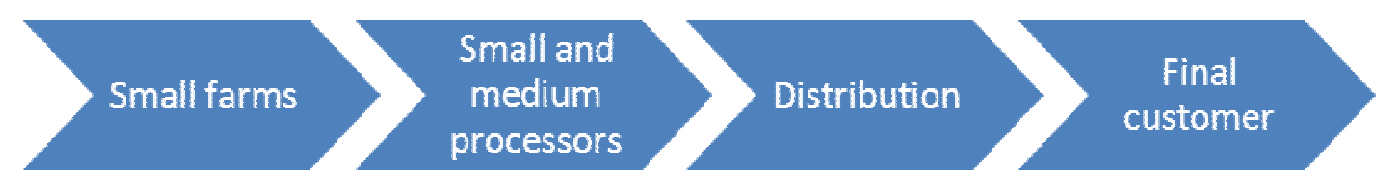

Figure 4: Dairy value chain in the period of 1986-2000 Mapping the value chain in the Vietnam dairy industry
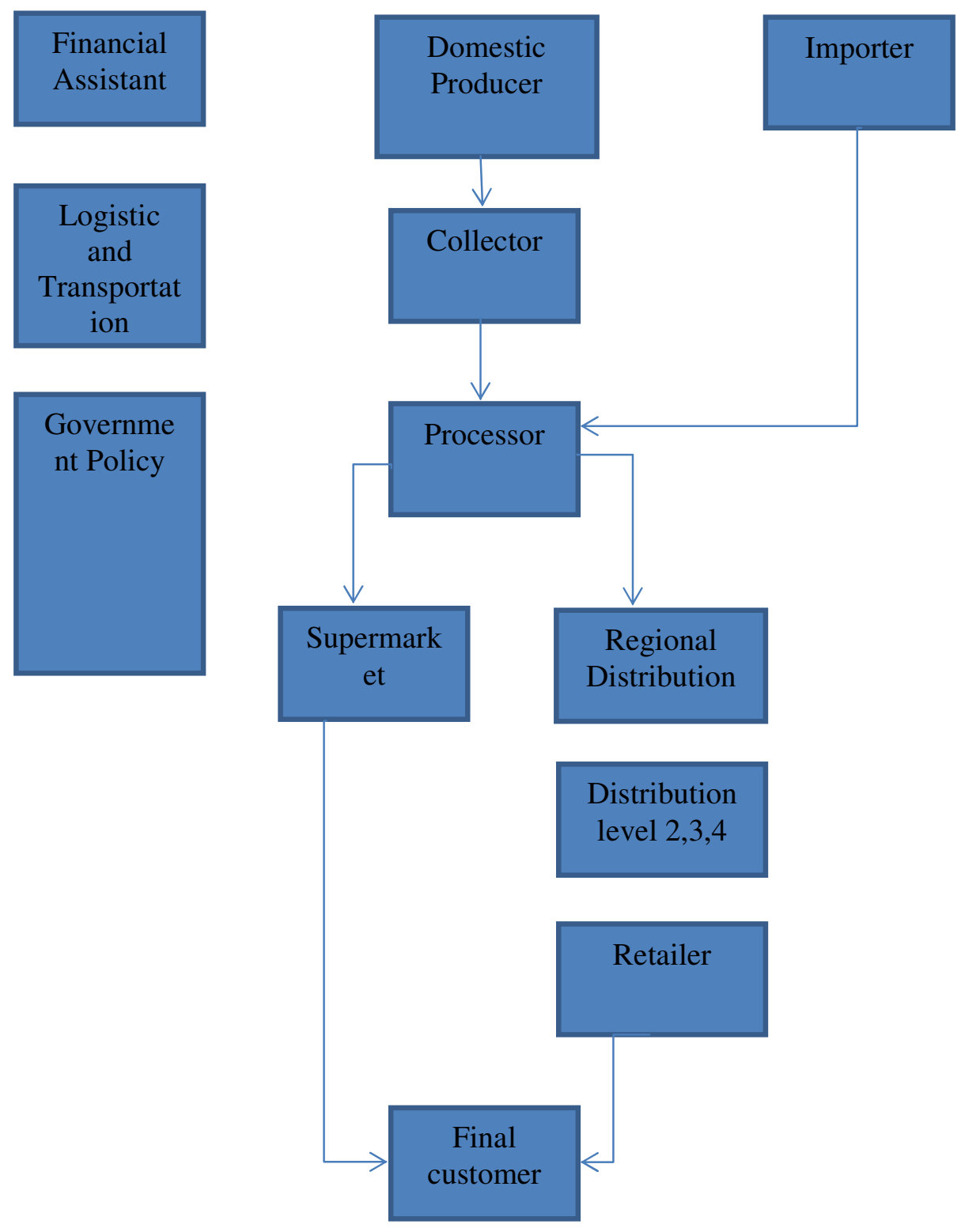

Figure 5: The value chain of the dairy industry in Vietnam 
As the development of the economy and dairy industry, large companies changed the situation of the dairy industry and the value chain distribution. The value chain then is improved and all large enterprises, medium and small farmers benefited from this transformation.

In this step we will try to analyse the role of factors in the value chain. In Vietnam, there are two main source of milk input: Domestic producer and imported milk powder. According to Chinh (2012), most of the milk consumption (nearly 80\% in 2012) in Vietnam is imported from foreign countries and the domestic producer only satisfy more than $20 \%$ of the domestic consumption.

\section{The milk producer}

This is the starting point of the value chain, where the raw milk is produced. The milk producer might be the farmer or the corporative association. Most domestic milk comes from the small and medium dairy farm. According to Khoi (2013) 95\% of dairy farms are household (8-10 head/ farm) and the dairy farmer can be divided in three main categories:

- The independent farmer: they buy cows and nurture by without any support from processor and sell their raw milk independently. Some of them open fresh milk store sand directly provided the milk to the final customer. The value chain here is quite short and the milk producer gain all of the value added; however, the number of this type of farmer is quite small because not every farmer could access the market easily and gain profit

- The contract farmer, this type is the most popular one and becomes the symbol of the co-operation between farmer and processor. During the contract, the farmers receive the small cow, feed, medical treatment from the milk processor. They nurture cows in their own land and sell the raw milk to the same milk processor. The contract farmer plays an assembling role and gains the assembling profit, which is usually low. This type of farmer appears in Ho Chi Minh City

- The dairy workers work for the large agriculture farm. They do not own any land and ought to hire from these large farms. They also receive small cows, feed, medical treatment from the large farm and sell the raw this to this one. The profits they receive depend on the number of cow and land area they are holding. They are considered the agriculture workers of this large farm. This type of farmer appears in Moc Chau and Ba VI Dairy Farm

- Corporative association is a higher level of milk manufacturing. Vinamilk and TH True Milk are the pioneers in this area. They apply the modern technology, feeding, caring the harvest in a large scale. Thousand of cows are raised in a sole huge farm at the same time. The feeding and medical care is carefully supervised by virtual system. Their proportion in the total national cows is just one third; nevertheless, they are developing in a fast place and become the main domestic producer in the near future.

\section{Milk importer}

The imported milk plays about $80 \%$ of the total milk product consumption in Vietnam. This amount of milk consists of milk powder input and final milk product. Mead Johnson and Abbotts and Friesland Campina are the largest milk product importer, estimated 67\% of the milk powder market. The main source of dairy product flow into Vietnam is from New Zealand and the US. Large proportion of the imported milk powder is used for producing liquid milk because the domestic production does not reach the customer demand. This fact has cause misunderstanding in the liquid milk market. The customer cannot differentiate between fresh milk and reconstituted milk and some milk producer rely on this fact to gain extra profit when selling reconstituted milk (a lower nutrition level) equally with the fresh milk. 
International Journal of Managing Value and Supply Chains (IJMVSC) Vol.5, No. 3, September 2014

\section{Feed}

Feed is the most important box in the farmer value chain. As mentioned above, Vietnam does not the long history of dairy development and the weather in Vietnam is not fully suitable for the grass growth. Some provinces: Son La, Ba Vi, Ho Chi Minh City owns the good weather for the growth of dairy grass. Cause this limitation, about $70 \%$ of dairy feed provided is imported the foreign countries (Khoi 2013). This fact creates the dependence of Viet Nam dairy industry on the world grass market. Further more, using the processed feed would lower the quality of fresh milk, which leads to a lower the benefit of dairy farmers. In the value chain, this is an important part of the producer total cost

\section{Government price control}

The specific point of Viet Nam is that the government also interferes in the economy. Supportive activities from the government could raise the dairy industry into a more modern stage. On the contrary, it would ruin the dairy very fast.

The main intervention of the government lies in price control and price stabilization. On Oct 4 2013, the Ministry of Health brought out the decision number 30 about controlling the dairy products for the under- 6 year old children. This decision aims at limiting the increase in dairy product recently. In late 2013 and early 2014 the price of dairy product in Vietnam varied a lots increasing from 7-10\%. Vietnam remains the highest dairy price in the world.

In April 30 2014, the Ministry of Finance (MOF) has new regulation on the dairy products for under-6 year old. The ceiling price is given out with a view to control the dairy price. This is considered a strong action of MOF in controlling dairy price and it also shows an inefficiency of MOF in controlling dairy price. With this new regulation, the price of powder milk would decrease from 50,000 - 70,000 VND per 900 grams box and as a result the milk producers would suffer. More over, the dairy farmer as their low voice would lose the most in this activity

\section{The milk processor}

This is the centre of the value chain and also the ruler in the game with dairy farmer. Milk processors buy milk direct from farmer or indirect from the collectors then process, package and transfer raw milk into final product. The processors set the quality control to the milk assessment. And base on the quality of the milk, they would set the price. The dairy farmer would be the one who suffer a lot in this trade. They are just small milk producer and their voices are not strong enough to change the price. This fact leads to the "buy low sell high" of the milk processor.

Viet Nam domestic milk market is manipulated by 3 large producers: Vinamilk, Dutch Lady, and Moc Chau.

Vinamilk is the leading milk entrepreneur with $40 \%$ of the market and still developing strongly. According to the 2012 Vinamilk annual report, the total revenue is 27.102 Billion VND increasing 23\% compared to the previous year and the after tax profit of Vinamilk reached 5.819 billion VND increasing 38\%. This is an outstanding result in the hard time of the whole economy. This statistic also shows that, all thought the economy might grows slower, the demand for milk still increase very fast (Figure 8)

Vinamilk and TH True Milk are the two of the largest domestic milk processors 
Vinamilk (VNM) developed from a former state own enterprise, the Southern Milk and Coffee Company; however it has successful developed and restructuring itself into a join-stock company. VNM now take the proportion of $40 \%$ aggregate dairy market in Vietnam (Chinh 2012) and become the main player in the dairy market. VNM has the annual growth of revenue is 34\% (2012) and reach the total revenue of 27,102 billion VND. VNM now owns 5 sub companies consisting 3 dairy companies: Lam Son Milk Join Stock Company, Vietnam Dairy Cow Join Stock Company, Miraka Join stock Company. VNM is also the pioneer investor in moving the production to foreign country. VNM hold 19.3\% of Miraka Join Stock Company, a New Zealand milk production and VNM can guarantee its milk provide in the near future.

Dutch Lady or Friesland Campina Vietnam is the first FDI firm appeared in Vietnam. Dutch Lady opened its first factory in Binh Duong in 1996 and now becomes the second largest milk processor in Vietnam. Each year, Dutch Lady provides approximately 1.5 billion dairy meals for Vietnamese people and still developing. In the value chain Dutch Lady buys raw milk from farmer; however, most of its products are made from the reconstituted milk. Dutch Lady imports most of its milk inputs from foreign countries and transfer into the final products In term of domestic production and total dairy cattle, TH True Milk is another huge milk processor.

Table 2: Top 3 largest dairy cattle in Vietnam 2012

\begin{tabular}{|l|l|l|}
\hline Producer & Number of Cows & Rank \\
\hline Vinamilk & 8200 & $3^{\text {rd }}$ \\
\hline Moc Chau Milk & 14.000 & $2^{\text {nd }}$ \\
\hline TH True Milk & 35.000 & $1^{\text {st }}$ \\
\hline
\end{tabular}

Source: Author calculation from VNM, Moc Chau and TH report

Although TH newly appeared in the fresh market, it creates a reliable branch mark of "Clean Milk". TH True Milk was introduced in 2010 with a long-term support from Bac A Bank and it is now on the way of building up its own dairy cattle. Until 2012, TH owns the quantity of 35.000 cattle - the largest cow farm in Vietnam, hoping to triple its cattle in 2020 and becoming the largest fresh milk provider in Vietnam. TH transfers modern technology and import 100\% baby cattle from New Zealand. TH is the pioneer in applying high-tech agriculture in Vietnam. Although the productivity of dairy cattle is relatively low from 4.5-to 5.0 tons/head/ year (Chinh 2012), TH is researching and increases the productivity in the near future. TH is now spreading its popularity through its TH True Mart System- a retailing chain in Ha Noi and Nghe An. TH is a specific model in the dairy value chain. It has a circulation from raw milk to the final customer. This is a remarkable point in the Vietnam dairy value chain.

\section{Distribution}

There are two main ways that the milk producer can distribute their products to the final consumers: Supermarket and Retailing process. 


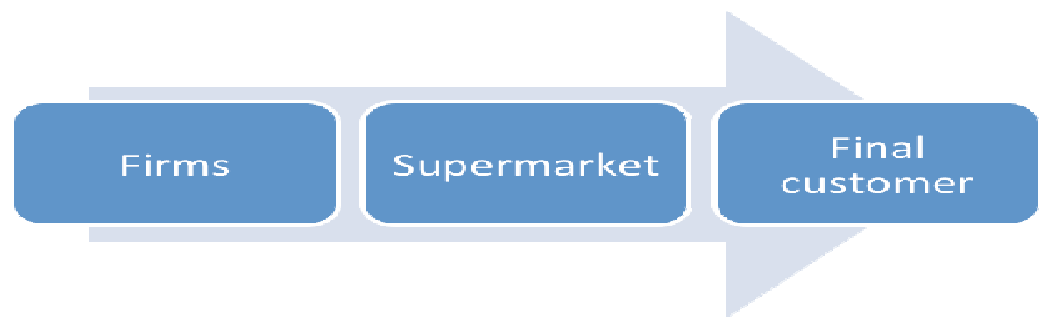

Figure 6: Supermarket Distribution Map

\section{Super market}

The dairy products go from dairy firm directly to the supermarket and reach the final consumer. In this process, there is one intermediate- the supermarket and it help to reduce the transportation fee and lower the retailing price.

In the modern trade, the role of supermarket is increasingly important. Because of the high concentration of good and the variety of name recognition products, supermarkets become pleasure places for purchasing good and dairy product in specific. The rise of Big C, Co op Mart is shortening the trade area of traditional markets and grocery store.

The top Vietnam Super markets are listed in the table below. Rank by number of branches. The positions are

Table 3: Top 3 largest supermarkets (number of branches)

\begin{tabular}{|l|l|l|}
\hline Supermarket & Number of branches & Rank \\
\hline Big C & 26 & $2^{\text {nd }}$ \\
\hline Co op Mart & 59 & $1^{\text {st }}$ \\
\hline City Mart & 26 & $2^{\text {nd }}$ \\
\hline
\end{tabular}

Source: Authors' calculation

The second one: Traditional way 


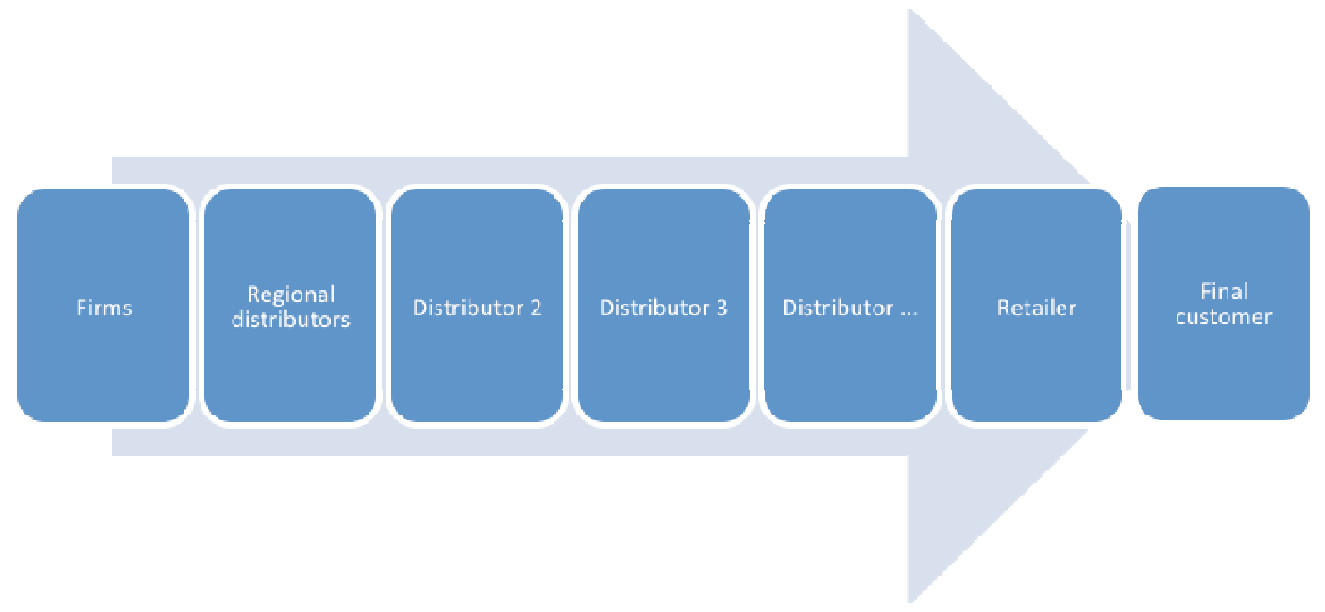

Figure 7: Traditional Distribution Map

In this process, dairy products go from producer firms to the regional distributor, intermediate distributors, retailer and final consumer. In this process, the number of distributor may vary depending on the place and population density. Usually, the retailing price in this process might slightly higher than the supermarket price because of the transportation and distributor profit.

The value added is each step might vary. In the supermarket case, the value added is higher as dairy product can go directly from the processor through the supermarket system to the final product. In the traditional way, as there are many intermediaries, each intermediary receives less and the flow of good is much slower than in the modern way.

In general, in a small value chain between farmers, collectors, processor and distributor, the processor remains the controlling role. The dairy market might be in a group monopoly when 3 main firms: Vinamilk, Dutch Lady and Moc Chau owns 75\% of the total market. Milk producers in general are forced to sell their product to these 3 large firms. These large firms give out the price, quality assessment; therefore they can gain the monopoly profit. The assumption is that in this value chain. The processors gain the highest value added

\section{Statistical facts}

The research assumption: The processors gain the highest value added. This step will try to analyse and use the statistic number to show to fact in the dairy industry. In 2012, Tran Huu Cuong and Bui Thi Nga conducted a survey in Moc Chau, Son La from 2008 to 2010 to research in the situation of the dairy production. Using the value chain approach, the result is show in the following map. 


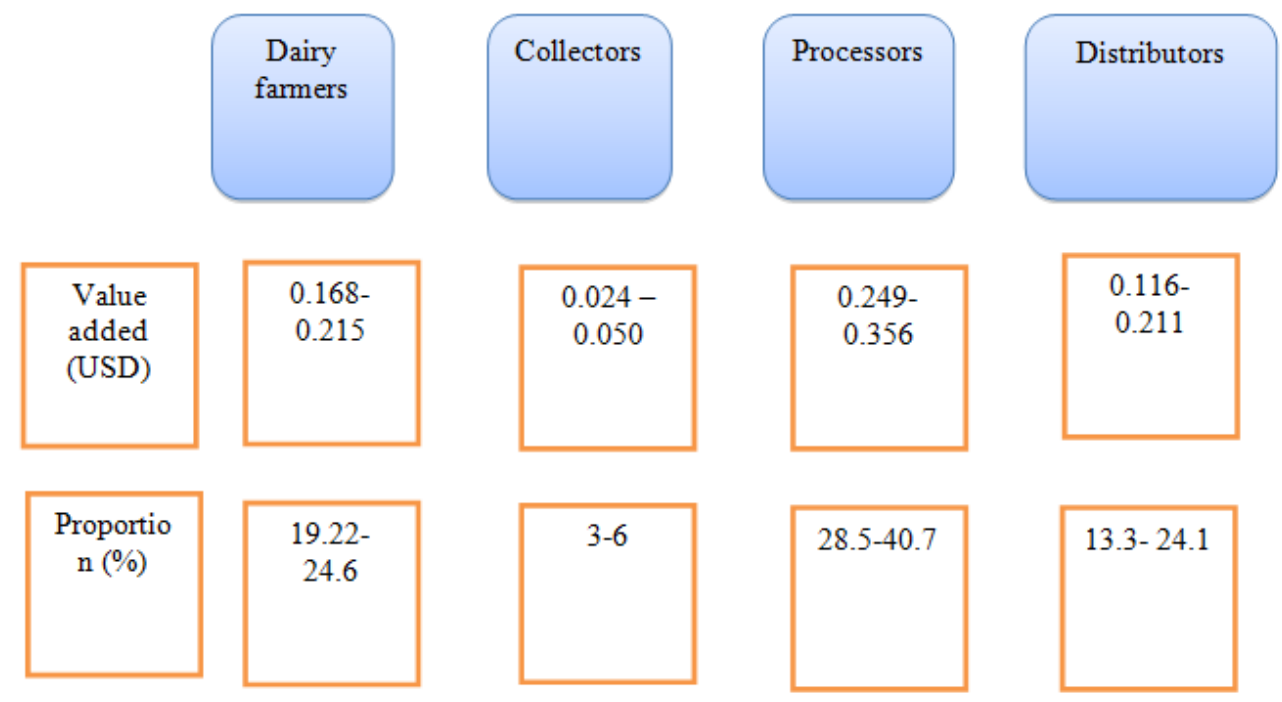

Figure 8:The income distribution in the value chain of the dairy industry in Moc Chau Source: Cuong, Nga (2012)

The research result shows an inequality in the distribution of value added in the value chain. Processors are the main player in this value chain. They gain from $28.8 \%$ to $40.7 \%$ in the total value added. This numbers vary as changing in milk input and the fluctuation in the market price. Dairy farmers gain the second largest value added (19.2 -24.6\%). This is a medium level comparing to other agriculture product; however, in this value chain, the proportion does not deserve the cost proportion (40-50\%) in the value chain. More over, in this research, the way of calculating the labor cost does not take the farmers opportunity cost, the expected land profit. Combining these two costs might increase the proportion in the chain total cost. Therefore in general, the dairy farmers incur a relative loss.

The collectors, as an intermediate between farmer and processor play a small proportion from 3$6 \%$ in the total value added. This results from the low participation in the value chain, mainly short-time storage and transportation.

The distributors gain a remarkable part in the value added $(13.3-24.1 \%)$. This might result from the variety level of distributor. To reach the final consumer, in the traditional distribution, dairy product must go through at least 4 level of distributor (wholesaler level 1, 2, 3 and retailer); therefore the aggregate value added might be relatively high.

In 2009, Truong Minh Huy also had a research in the dairy industry using value chain approach. The research used the quantitative approach-cost and benefit analysis to determine the value added in each actor of the value chain Huy suggest a simple value chain map with 2 main actors: Dairy farmer and processor. 


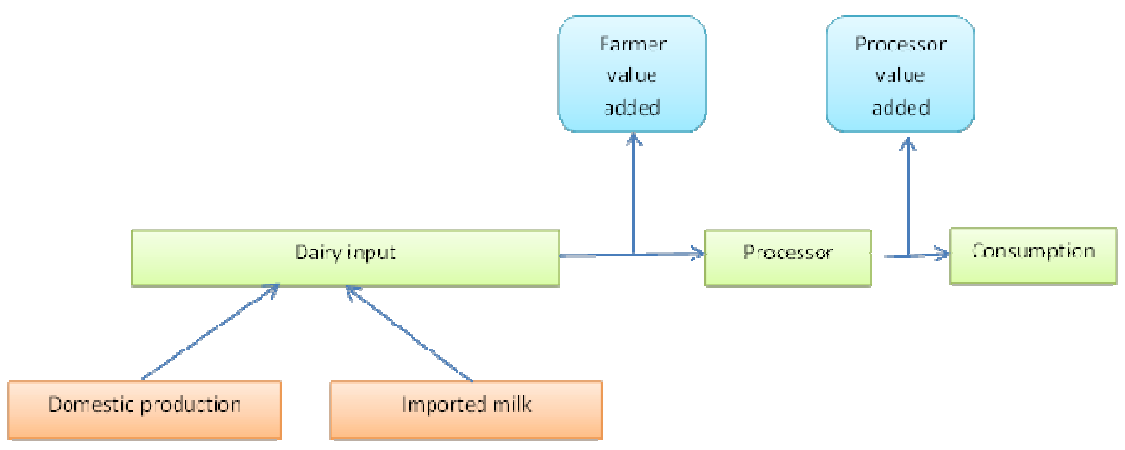

Figure 9: Dairy simple value chain Source: Huy (2009)

For the dairy farmer: the value added of the dairy farmer through analysing their cost and revenue:

Table 4: Estimated cost for a dairy cow/year

\begin{tabular}{|l|l|l|l|}
\hline & Price & Quantity & $\begin{array}{l}\text { Money (Million } \\
\text { VND) }\end{array}$ \\
\hline Manufactured food & $5.500 \mathrm{dong} / \mathrm{kg}$ & $2400 \mathrm{~kg} / \mathrm{year}$ & 13 \\
\hline Fresh food & $450 \mathrm{dong} / \mathrm{kg}$ & $8760 \mathrm{~kg} / \mathrm{year}$ & 4 \\
\hline Electricity & & & 0.5 \\
\hline Repair and maintain & & & 1 \\
\hline Land fee & & & 1 \\
\hline Other & & & 0.5 \\
\hline Total & & & 20 \\
\hline
\end{tabular}

Source: Huy (2009)

In this total cost, the largest proportion was the manufactured food with 13/20 mill VND reaching $65 \%$ of the total cost. The main reason for this large proportion is the lacking of fresh grass. Vietnam does not own the advantage atmosphere and the limited land ownership that resulted to this fact.

The total revenue of a dairy cow each year is exhibit in the following table:

Table 5: Estimated revenue of a dairy cow/year

\begin{tabular}{|l|l|}
\hline & Quantity (million VND) \\
\hline Milk income & 24 \\
\hline Selling cow & 2 \\
\hline Other & 2 \\
\hline Total & 28 \\
\hline
\end{tabular}




\section{Source: Huy (2009)}

In general each year a dairy cow can bring up the benefit of 8 million VND; however this target can only be reached without the increase in food price and maintain the raw milk price. Dairy farmers seem to be weak in these relationships. They cannot negotiate the price for manufactured good because most of the good are imported from foreign and their voice could not reach the first producer. In the relationship with the processor, dairy farmer also stand in the lower position. After the raw milk is harvest, they must quickly pass it through the processor factory and here the processor will test and qualify the raw milk input. They would consider which milk they buy, which one they do not and the farmer cannot interfere in the process. They have to accept the result even if they can get nothing from their hard working.

For the dairy processor: Because of the inability to access to the real firm statistic, more specific analysis was impossible; however, Huy did build up a material input map of dairy processor to see how much they can gain.

Table 6: Milk contents price

\begin{tabular}{|c|c|c|}
\hline & Price & Cost (VND) \\
\hline \multicolumn{3}{|l|}{ Dairy imported materials } \\
\hline Whole milk product & $3,400 \mathrm{USD} / \mathrm{ton}$ & 61,200 \\
\hline Skimmed milk product & $3,000 \mathrm{USD} / \mathrm{ton}$ & 54,000 \\
\hline High protein milk & $5,000 \mathrm{USD} /$ ton & 90,000 \\
\hline \multicolumn{3}{|l|}{ Other contents } \\
\hline DHA & $80 \mathrm{USD} / \mathrm{kg}$ & $1,440,000$ \\
\hline Calcium & $7 \mathrm{USD} / \mathrm{kg}$ & 126,000 \\
\hline Vitamin & $10 \mathrm{USD} / \mathrm{kg}$ & 180,000 \\
\hline
\end{tabular}

\section{Source: Huy (2009)}

Depending on each producer recipe, the price of each powder milk product varies from 80.000$100.000 / \mathrm{kg}$. On the other side, the actual price of domestic product is $140.000-150.000$ and foreign one is 300.000 . Powder milk is the most profitable product in the dairy industry.

The two qualitative researches clearly show the inequality in the income distribution of the dairy value chain. The dairy farmers are in a weaker side in the relationship with processor. They can earn profit; however, the profit can only be reached with the agreement of the processors

\section{A deeper look into the dairy industry in Vietnam}

The above parts have shown the fact happening in the dairy industry in Vietnam, the value chain, the inequality in income distribution, and supportive policies of the authorities. This part would deeply analyse the processor activities and the facts using value chain approach 


\section{Why do the processors can earn such high value added in the value chain? What is the truth behind this situation?}

The term of "governance" and "economic rent" would mostly explain these facts. Governance can be simply understood as the control of links and activities in the value chain. The factor holding the governance could ensure sequence along the value chain and actively manage the operations of the links within the chain to reach the final sequence.

In this value chain, processors proof themselves as holding the governance through three forms: Legislative governance, judicial governance, and exclusive governance

Table 7: Processor governance in the dairy value chain

\begin{tabular}{|l|l|}
\hline Legislative governance & Real activities \\
\hline Judicial governance & $\begin{array}{l}\text { Setting standard for raw milk input, } \\
\text { purchasing price, compulsory delivery } \\
\text { condition for special products (milk tank } \\
\text { for raw milk and freeze tank for yogurt). }\end{array}$ \\
\hline Executive governance & $\begin{array}{l}\text { Supervising the farmers activities and } \\
\text { distribution method through the supervisor } \\
\text { net. }\end{array}$ \\
\hline $\begin{array}{l}\text { Sending dairy experts to support the } \\
\text { farmer in dairy cattle caring. Providing } \\
\text { medical service for the dairy cattle. } \\
\text { Promote the flow of good through sale } \\
\text { manager. }\end{array}$ \\
\hline
\end{tabular}

In this case, the governance of dairy processor has developed to the monopoly ${ }^{2}$ status. According to Huy (2009) three main milk processors purchased $70 \%$ of total milk produced in Vietnam. The limitation of choice creates the dependence of dairy farmers on the processors. They must accept the price and quality assessment of the processors in order to sell their milk. This is the main reason leading to the huge profit of the processors

Economic rent here can be understood as high barrier entry. Huge quantity of capital and technology is needed for the establishment of the processor factory. From this high barrier processor could earn a surplus or we might call it economic rent.

Further more, supportive trade policies also add up to the profit of milk processor. In 2009, the circular number 39/2009/TT-BTC of the Ministry of Finance increased the tariff of the dairy

\footnotetext{
${ }^{2}$ Monopoly: A situation in which a single company or group owns all or nearly all of the market for a given type of product or service
} 
product. According to this circular, the fresh milk imported into Vietnam has to suffer the tax of $15 \%$. This was a strong protection of the domestic dairy cattle and fresh milk production.

\section{Why TH True Milk tries to do everything on its own?}

TH True Milk was established in 2010 with the view of becoming the first provider of fresh milk in Vietnam and in just 3 years, it owns more than 35,000 cows (a remarkable number). Furthermore, TH also introduced the TH True mart retailing chain in Ha Noi and Nghe An which made the first step of a processor into retailing market and with this retailing store chain, $\mathrm{TH}$ has completed its value chain from the beginning to the last end. What makes TH so different to other processors? The answer lies in the "systemic competitiveness" of TH True Milk.

According to Kaplinsky and Morris (2001) value chain handbook, in order to have a sustainable value chain, a firm should remain the systemic competitiveness. The efficiency of all parts in the value chain is not all. Every part should be connected smoothly so as to reach the whole chain efficiency. TH True Milk is following this process. By doing the process on their own, TH can actively control the schedule, strongly supervise the milk quality, change the product in a short time and reach the chain efficiency.

The reasons why Vinamilk decided to invest in New Zealand. The activity of investing in Miraka, a New Zea Land dairy producer mark the first time a Vietnamese company invested in foreign in the dairy aspect. The value chain analysis considers this activity as "upgrading function" of Vinamilk. Generally, before the establishment of Miraka company, Vinamilk relied most of its raw milk powder on the foreign market (domestic production take a small proportion in the Vinamilk total sale) and It just focused on the processing activity; however, in order to gain more in the value chain, Vinamilk try to upgrade itself, receiving more activity in the value chain- the raw milk production. As mentioned above, New Zealand has the atmosphere advantage in producing dairy product and become the largest exporter to Vietnam in 2012. Owning a firm in New Zealand, Vinamilk own the relative advantage to its competitors

\section{What it the purpose of the direct support to the dairy farmer of the government?}

In the dairy value chain, dairy farmer seem to be the weakest part, they are vulnerable to every change in the value chain especially when Vietnam integrates more and more in the international market. That would lead to a loss in return of the dairy farmer. The value chain analysis shows that, in order to maintain a sustainable income growth in the globalization, an industry should protect the threaten part and promote other links. This activity of the government in the early 2000 s is considered a foreseen of the future.

\section{Will the decision of applying international standards in the dairy products ruin the domestic industry?}

In 2007 as mentioned above, the Ministry of Science and Technology (MOST) published the new quality standard of dairy products. These standards are categorized in TCVN and ISO equivalence. In the case of the low development of the domestic industry, will this decision slowdown the dairy development?

In some case, this is a right conclusion; however, when applying this decision, the MOST consider the access to international market of Vietnamese products. The value chain analysis shows that only efficiency in production does not lead to a sustainable development. One important part is getting access to the final customer and in this case the international dairy market. For importer, applying these standards made it much comfortable as now they can easily 
supervise the quality of their product. Further more, for exporter like Vinamilk; the application of this decision brought them closer to the international markets

\section{CONCLUSION}

The value chain analyse is a very effective way in research about value added distribution. It shows the equality or inequality in the value chain and base on that, policy makers could bring out suitable strategy

This paper aim at researching the dairy industry in Vietnam based on a value chain approach. The simple value chain includes 6 main actors: Dairy producer, milk exporter, collector, and processor and distribution system. In this value chain, the processor gain the highest value added. This fact might result from the group monopoly of the milk processor.

The paper also shows out one special point of the Vietnam dairy value chain- the participation of the government policy. From a time period analyse we can see that the government step by step see the strong development of the dairy industry and assist it more and more effectively. The dairy industry in Vietnam is now reaching the international standard together with the integration in ASEAN, WTO and TPP.

Value chain proofed itself as an effective way to analyse the activities of firm and government. Based on this analysis, activities or policies, which can help to create a sustainable dairy, should be launched.

Solutions:

- Increase the voice of dairy farmers in the relationship with processors by forming a dairy agency. This agency would represent a number of farmers to negotiate with the processors in price and dairy quality assessment

- Lower the dependence of dairy farmers on the processors by forming a direct relationship between the dairy farmers and final customers. Improve the access of dairy farmers to the final market.

- The government should have the financial support and encourage policy for the dairy farmers and processors to develop the domestic dairy industry, increasing the value added.

\section{REFERENCES}

1. Huu, T., \& Bui, T. N. (2011). Analysing actors of the value chain of fresh dairy milk in Vietnam. Journal of Economics and Development (169-II).

2. Kaplinsky, R., \& Morris, M. (2001). A handbook for value chain research (Vol. 113). Ottawa: IDRC.

3. Khoi, N. V. (2013). Wicked problems: a value chain approach from Vietnam's dairy product. Springer Plus, 2(1), 1-6.

4. Lowe, M., \& Gereffi, G. (2009). A value chain analysis of the US beef and dairy industries. Center on Globalization, Governance \& Competitiveness, Duke University.

5. Minh Huy T (2009) Dairy value chain analysis. Research Department - Tai Viet Joint Stock Company, Hanoi, Vietnam

6. Gerosa, S., \& Skoet, J. (2012). Milk availability: Trends in production and demand and medium-term outlook. Food and Agriculture Organization of the United Nations. 
International Journal of Managing Value and Supply Chains (IJMVSC) Vol.5, No. 3, September 2014

\section{Authors}

Nguyen Viet Khoi (Vietnam)

Professor, University of Economics and Business, Vietnam National University, Hanoi Dr. Khoi joined Vietnam National University in 2000 and has been the Deputy Head of Department of International Business since 2011. He has also been providing key advices on export strategies to the Assembly of Vietnam. His research interests are global value chains, supply chains and the global strategies of multinational corporations. Dr. Khoi has been teaching and doing research at institutions such as University of Wisconsin, University of Southern New Hampshire. In 2012 and 2013, Dr. Khoi joined Columbia Business School, Columbia University as a postdoctorate researcher under the Fulbright Scholarship. Dr. Khoi has published books such as Global Value Chains of Transnational Corporations: A practical Approach from China's current situation (VNU Publishing House 2013), International Economics (co-author; VNU Publishing House, 2010), and Transnational corporations: theories and practices (co-author; VNU Publishing House, 2007).

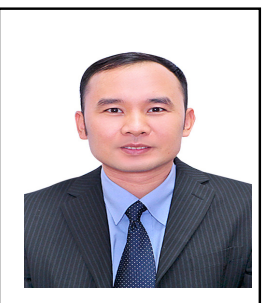

